\title{
The Building Blocks of a Model Learning System for Nigerian Schools
}

\author{
Steve Nwokeocha ${ }^{1}$ \\ ${ }^{1}$ Africa Federation of Teaching Regulatory Authorities Plot 492 Ahmadu Bello Way, Kado, Abuja, Nigeria \\ Correspondence: Steve Nwokeocha, Africa Federation of Teaching Regulatory Authorities Plot 492 Ahmadu \\ Bello Way, Kado, Abuja, Nigeria. E-mail: drsteve44@gmail.com
}

Received: January 30, 2019

Accepted: March 3, 2019 Online Published: May 20, 2019

doi:10.5539/jel.v8n3p147

URL: https://doi.org/10.5539/jel.v8n3p147

\begin{abstract}
The paper was written as part of the efforts to find solution to the the falling standard of education in Nigeria. The education stakeholders and government alike strongly held the view that the standards had fallen and recently the Minister of Education called for the declaration of a state of emergency in education in order to take extraordinary measures to restore the education system to its glorious past. Against that background, the paper was written to draw attention to the fundamental issues, principles and practices which largely determine the standards of education across the world. Often, the school system in Nigeria had paid less than required attention to such fundamental issues while focusing disproportionately on matters of funding and lack of infrastructure and facilities. It is the position of the paper that though funding, infrastructure and facilities are indispensable, a proper understanding of the fundamentals of the learning system and their proper management can empower schools to record high academic achievements irrespective of their settings and material circumstances. The paper therefore addressed themes such as learner characteristics, curriculum development, instructional resources, instructional strategy, teacher competency, learning assessment and reward system.
\end{abstract}

Keywords: learning, model, Nigeria, school, system

\section{Introduction}

This paper was first presented as a keynote at an international conference in Abuja, Nigeria organized by the Federal Ministry of Education and Educorp World, United States of America in October 2018. The aim of the conference was to explore ways to "redress and upgrade public education in Nigeria" to attain international standards (Educorp World, 2018). The aim was set against the regular refrain in Nigeria that the quality of education had plummeted. Thus, there has been constant suggestion that government should declare a state of emergency in education. Several times, even the current Minister of Education had said that the government was considering the declaration of the state of emergency in education. In 2017, the issue of falling standard of education compelled the Minister of State for Education to opine that Basic Education should be moved from the concurrent to exclusive legislative list in the Nigeria's Constitution (Federal Republic of Nigeria, 1999). Items in the concurrent list in the Constitution are matters that both the state and federal governments can legislate on whereas items in the exclusive list are matters that only the federal government can make laws about. The Minister of State made this proposal because he felt that Basic Education has failed to achieve the aspirations articulated in the National Policy on Education and Nigeria's Constitution. This opinion coming from a Minister who is also a Professor of Education and former Vice Chancellor of a public university was considered weighty and underscored the urgency of the situation. However, the suggestion by the Minister of State for Education was seriously opposed by a wide range of analysts and journalists, and national newspapers wrote editorial opinions condemning it (Adebisi, 2017; Independent Newspapers, 2017). These critics argued that the suggestion was against the federal structure of the country which requires that both states and the federal government should have the right to legislate on social services such as education. But there was no disagreement that the standard of education has declined.

According to the National Policy on Education, the goals of education in Nigeria are: (a) Development of the individual into a morally sound, patriotic and effective citizen; (b) total integration of the individual into the immediate community, the Nigerian society and the world; (c) provision of equal access to qualitative educational opportunities for all citizens at all levels of education, within and outside the formal school system; 
(d) inculcation of national consciousness, values and national unity; and (e) development of appropriate skills, mental, physical and social abilities and competencies to empower the individual to live in and contribute positively to the society (Federal Republic of Nigeria, 2013, p. 2). Following these goals, several educational authorities in Nigeria had set benchmarks of learning achievements for the various levels of the education system-basic, senior secondary and tertiary education levels. However, the performance of students at the various levels failed to meet the benchmarks, thus warranting the call for the declaration of a state of emergency in education. There is no gainsaying, therefore, that Nigeria is in search of ways to improve its education system and particularly teaching and learning.

A World Bank study titled "Facing Forward: Schooling for Learning in Africa" declared that there is a learning crisis in Africa. It described the quality of education as very poor and that "fewer than half of students in most countries are acquiring minimum competencies in reading and mathematics" (Bashir, Lockheed, Ninan, \& Tan, 2018, xxv). The study asserted that:

Bringing children into school and ensuring that they complete at least basic education and acquire the foundations of learning is essential for building this knowledge capital. This book shows that with focused attention on a few key policy areas, tackling this fundamental challenge to Sub-Saharan Africa's future is as feasible as it is promising.

Makhtar Diop, World Bank Vice President, Africa Region in a Foreword to the World Bank Research (Bashir, Lockheed, Ninan, \& Tan, 2018: xxv)

The World Bank study blamed the learning crisis on overcrowding of classes and poor implementation of policies on language of instruction, among others. It stressed that countries should not just provide schools but also determine whether learning is actually taking place. As part of its core contributions, the study highlighted key factors that can promote learning outcomes and effective education service delivery. The four key factors it identified are: (a) a focus on student progress from early childhood education to end of basic education; (b) teacher support and management; (c) efficient use of resources; and (d) building technical and other capacities in the ministries of education.

In a similar vein, this paper is primarily concerned with how best to translate schooling into learning in Nigeria. It focuses on what may be termed the building blocks of a model learning system for any school. A model learning system is an ideal complex of educational structures, resources, principles and practices that has the capacity to translate educational vision, mission, goals and objectives into the desired learning outcomes. This complex as analyzed in this paper has the following critical pillars or building blocks: (a) Learner characteristics; (b) Curriculum; (c) Instructional resources; (d) Instructional strategy; (e) Teacher competency; (f) School climate; and (g) Assessment and reward system. Every learning system deals with these building blocks and the academic achievement of the learners depends significantly on how these issues are managed. What constitutes the ideal case for each of these building blocks, however, may be subject to debate and further research. But in the case of this paper, the author relies heavily upon practical experiences of over thirty years in the Nigerian education system to offer suggestions. The author has been a teacher at all the levels of the Nigerian education system - secondary education, colleges of education and university. The author has also directed the regulation of teaching at the national level and currently heads the federation of the national agencies that regulate teaching in Africa. Consequently, the suggestions are strengthened by the author's experiences gained through participation in research, and development and implementation of educational policies in many African countries and for several continental and global organizations.

\section{The Building Blocks are Universal Principles}

The building blocks analyzed in this paper transcend levels of education system, nations, settings and time. All modern education systems deal with them in some significant measure. Whether a school is located in the city or rural area, advanced or developing country, poor or affluent neighbourhood; or whether the school is for the young or old, the handling of these building blocks can make or mar the learning system. They are the enduring foundations of any a high performing learning system. To build a model learning system, therefore, they should be well understood and competently managed.

Importantly, the paper chose not to bore the reader with the plethora of the very well-known problems of the Nigeria's education system - lack of funds, poor infrastructure, bad roads, insecurity and so forth — but rather to focus on how schools can improve performances no matter their material situation. For, if the nation has to wait to get all things perfect before dreaming of a high performing education system, it may have to wait forever. Yes, the situation may be bad enough, but under any circumstance, if the education system is effectively managed with the critical building blocks in mind, the effects of the bad situation will be minimized while academic 
excellence is promoted. This is the central thesis of the paper. Put differently, the best equipped schools are not the best performing schools all the time, why? Not that equipped schools are not desirable, but schools may be equipped and yet fail to understand what matters most.

Indeed, academic excellence has manifested in various settings and not only in the schools for the rich or in the schools with the best of infrastructure. For instance, the best students in the national examinations such as the Unified Tertiary Matriculation Examination (UTME), West African School Certificate Examinations (WASCE), and National Examinations Council (NECO) at times have come from the rural of parts of Nigeria and even schools that no one expected to achieve such record of excellence. Similarly, the best performers in the national professional examinations organized by the Nigerian Law School (NLS), Medical and Dental Council of Nigeria (MDCN), Teachers Registration Council of Nigeria (TRCN), among others, sometimes have come from universities not ranked among the best in the country by public opinion. In the USA and United Kingdom, hundreds of thousands of children obtain their basic and secondary education at home - called "homeschooling" in the USA and "home-education" in the United Kingdom - and still perform above national average in the national standardized tests (Ray, 2018). Homeschooling is where the families take the responsibility of their children's education such that their children receive education at home without enrolling in any school. The children are taught at home by teachers hired by their families or groups of families and provided with the curriculum, conducive environment and instructional resources. The United States National Center for Education Statistics (2017) and other sources (e.g., Ray, 2018) indicated that 3\% of American children passed through homeschooling in the 2011/2012 school session; and $83 \%$ of these were White while Blacks constituted 5\%, Hispanics 7\% and the Asian or Pacific Islanders 2\%. Furthermore, the number of American children who passed through homeschooling in 2016 was 2.3 million while $2-8 \%$ is the growth rate of homeschooling in the USA. In the United Kingdom, over 20,842 of the children were involved in home education in 2012 (Sarwar, 2013). The lesson from these evidences is that learning relies on some universal principles and great learning can go on anywhere in the world if the issues are got right.

It is important, therefore, to rethink the remedies of the falling education standard in Nigeria. It is critical to reconceptualize education and to make education more worthwhile and able to transform lives and situations (UNESCO, 2013, 2015). In a foreword to UNESCO's (2015) great work titled, "Rethinking education: Towards a global common good?" Irina Bokova, UNESCO's Director-General called on the world to think again and think big about education. Bokova was of the view that to meet the transformation of the 21 st century the world must change the way learning is organized. Bokova further stated that:

The world is changing-education must also change. Societies everywhere are undergoing deep transformation, and this calls for new forms of education to foster the competencies that societies and economies need, today and tomorrow. This means moving beyond literacy and numeracy, to focus on learning environments and on new approaches to learning for greater justice, social equity and global solidarity... This is a humanist vision of education as an essential common good (Irina Bokova in UNESCO, 2015, p. 3).

In essence, it can be strongly asserted that Education is not just funding, infrastructure, school buildings, a bunch of textbooks and perhaps a hall adorned with computers. Education is much more than these. Real education is a catalyst that can inspire a child and ignite an inner fire that the outward situation cannot quench. Real education can supply strength to a child where there seems to be none; and can awaken the genius in a child and sustain a life-time and life-wide search for excellence. These are the critical qualities of inner motivation that make the difference between success and failure irrespective of circumstances in schooling.

\section{Learner Characteristics}

The first task in building a model learning system is to know the learner, his or her background in all ramifications - family, gender, socio-economic status, religious beliefs and general world view. Inability to understand and integrate the characteristics or background of the learner in the learning design carries serious negative consequences. The learning system must take cognizance of the background of all children expected to engage in the learning process. This integration is a matter of right of every child because the Universal Declaration of Human Right (United Nations, 1948) and other international conventions and education goals (UNESCO Institute for Statistics, 2018; United Nations, 2015; United Nations Girls Education Initiative, 2010) have made it clear that education is a fundamental human right of the child. But more importantly, the integration of the background of the learner in the learning system is to make the child naturally willing to learn; it is also to elicit the child's inner motivation and voluntary participation. Indeed, the integration is to inspire the child to take responsibility of his or her learning. Motivation is, therefore, a necessary condition for learning to 
take place. No child can excel where he or she is under compulsion to study. No child can excel in a learning system that mocks, debases or negates his or her humanity. No child can be motivated to learn where the learning process is at variance with his or her natural and social characteristics and self-concept.

The fact that motivation underlies excellent academic performance, and how this motivation works can be demonstrated with any motivation theory. Bates (2015) in a work titled "Learner characteristics and motivation: How to achieve efficient and effective learning" gave a good illustration of the connection between learner characteristics and motivation to learn. Bates reported the outcome of the 2014 Conference of the Canadian Society for Teaching and Learning in Higher Education which adopted the motivation model propagated by Weibelzahl and Kelly (2005). The model depicted the traditional self-directed conditions for learning. The conditions are attention, effort, participation, and persistence. What the model demonstrates is that "students bring their inputs while the learning organization supplies the environmental factors" (2015, p. 167).

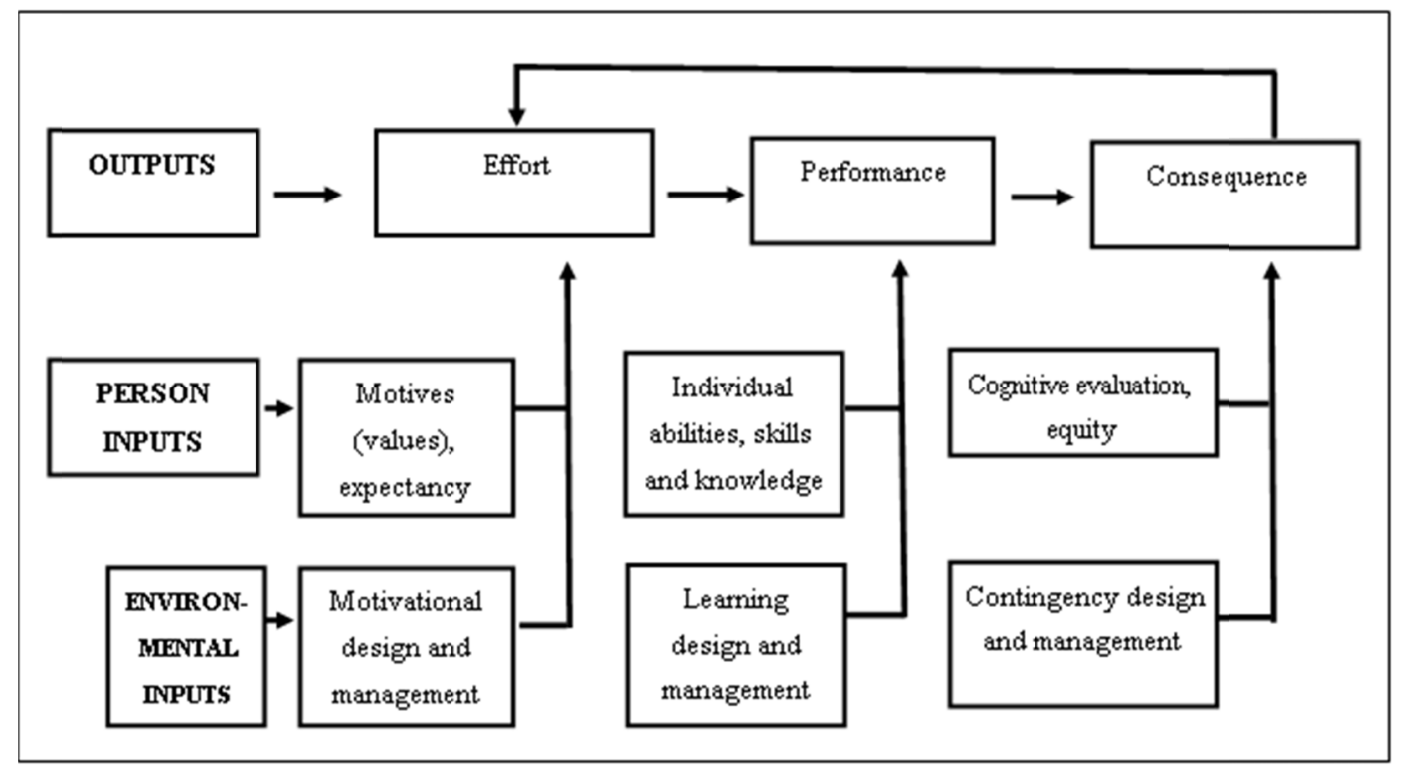

Figure 1. The traditional self-directed conditions for learning

Source: Author's adaption of the Motivation Theory by Keller (1983) reported by Vincent (2003), Weibelzahl and Kelly (2005), and Bates (2015).

Figure 1 shows that in a learning system:

i. Effort leads to performance and then to consequences.

ii. Effort is a function of the learner's motives, value systems and expectations as well as the motivational qualities of the learning design and management.

iii. Performance is determined by the learner's abilities, skills and knowledge within the context of the learning design and management.

iv. Consequence is a measure of the learner's perception, evaluation and equity considerations in addition to how the learning system manages learning outcomes.

The basic lesson of the model is that learning outcome depends how on much the environmental inputs (learning design and management) reinforce the learner's motives, values systems, expectations, individual abilities, skills, knowledge, cognitive evaluation and concept of equity. This motivation theory demonstrates why it is very important to consider learner characteristics in designing learning systems for schools. Rurato and Gouveia (2014) extended the study of learner characteristics to adults engaged in open and distance education. They used the questionnaire designed by Schrum and Hong (2002) and investigated issues such as learning styles, goals and aims, lifestyle factors, study habits, technology experience, access to technology resources, and personal characteristics. They found that personal characteristics are very strong factors that affected learner outcomes. 


\section{Curriculum}

The curriculum is another important building block of a model learning system. The curriculum is to a learning system what the constitution is to a country. The curriculum is the framework and content of the knowledge, skill, values, attitudes and general orientations as well as the modalities, resources, contexts and other principles that guide their transmission to the learner. In its broadest sense, the curriculum is the totality of experiences that a learner is exposed to in the learning system. Curriculum experts, therefore, understand that curriculum is not just the written and official content of a book tagged "curriculum" or "syllabus" rather it includes both intended and unintended as well as manifest and latent dimensions. Accordingly, in designing a curriculum, expertise is required to provide a framework that could keep as much as possible the dimensions of the curriculum within the management and control of the school and to be in tandem with the desirable goals of education. Awareness of the tricky nature of a curriculum is critical to maximizing the benefits of curriculum design. Conversely, ignorance about this tricky nature leaves much of the learning process to chance and promotes learning failure. The first step towards building a virile learning system is to design a curriculum that is robust, dynamic and captures the realities of the intended and unintended, as well as the manifest and latent curriculum. The manifest curriculum is that written explicitly and admitted as being official while the latent curriculum comprises the learning experiences outside the official curriculum and they are not explicitly written. Alternatively, the latent curriculum may be termed "hidden curriculum" (Jackson, 1968) and this still refers to all the learning that occur outside the official curriculum.

The next critical issue is the question of how much of the local culture is integrated in the curriculum. It must be understood that from the sociological perspective, education primarily means the socialization of the members of the society and the transmission of culture from one generation to another. The issue then is, whose culture is being transmitted? To the extent that the curriculum is imbued with a culture alien to the learner, to that extent the curriculum is irrelevant and invalid. This has been the dominant problem in Africa where colonization has threatened the survival of the cultures of the indigenous people and the Western education system has largely replaced the indigenous education system. Consequently, education in Africa has been trailed by the crisis of irrelevance and inability to empower either the development of the learner, his community, nation or continent (Nwokeocha, 2018; Obanya, 2005). Much of the failure of the Western education system in Africa including Nigerian has been blamed on the lack of integration of the indigenous cultures in the school curriculum (Nwokeocha, 2018). Consequently, the learners are turned by Western education into what sociologists may call marginal individuals. This is a situation where the learners have dropped most of their indigenous to imitate the Western cultures but end up being neither indigenous nor Western. This is a confusing state of social development characterized by absurdities in lifestyles, norms, values, and clash of civilizations with its ugly consequences and underdevelopment.

Furthermore, curriculum development in a learning system is incomplete without addressing issues of multiculturalism. This is very critical in the present dispensation because the United Nations Sustainable Development Goals (SDG) 4-Education has inclusion, equity and quality as the inviolable defining parameters of any education system (United Nations, 2015). SDG4-Education is to "ensure inclusive and equitable quality education and promote lifelong learning opportunities for all" (United Nations, 2015, p. 18). There is also a huge array of UNESCO conventions, guidelines, declarations, and position papers (e.g., UNESCO 2013; 2015; 2017; UNESCO Institute for Statistics, 2018) that make multiculturalism a frontline issue in the education system. It therefore behooves a model learning system to ensure that the curriculum caters for learners of all backgrounds-gender, economic class, religious beliefs, political leanings, geographic location and all other factors. Again, some educators wrongly think that multicultural education is a single subject that has to be taught in schools whereas it a philosophy and content that should permeate the curriculum and entire learning system. This implies that all subjects in the school must reflect multiculturalism including mathematics and the sciences which people think have little to do with the concept. This is done by ensuring that as much as possible all school subjects have curriculum content, illustrations and resources drawn from multicultural background and that instructional strategies, teacher-student, student-student, and general social relations, and the social climate and governance mechanisms of the school truly reflect multiculturalism. Therefore, multiculturalism is a holistic issue and not a piecemeal matter that is done when convenient or when there is crisis among the diverse populations that make up the learning system (Nwokeocha, 2019).

\section{Instructional Resources}

Among the building blocks of a model learning system are instructional resources. Instructional resources in a learning system are proven to be critical based on the fact that humans learn more when exposed to practical experiences than only theories. Therefore, no matter how abstract a concept is, it gets better understood and 
appreciated if there is a medium to make it more practical. This reality is summed up in the famous quote attributed to the Chinese philosopher, Confucius (551 BC-479 BC), which says: "I hear and I forget. I see and I remember. I do and I understand." Part of the competency of a qualified teacher is to be creative enough to know that literarily every learning theme has its instructional resources within the environment and the integration of these resources in instruction greatly enhances the ability of the learners to comprehend, reflect and engage in enquiry and practice. What this demonstrates is that instructional resources are of diverse nature and not limited to manufactured or ready-made objects and media. However, with the rise and advances in technology, educational technology has become a cornerstone of teaching and learning. Educational or instructional technology can be amazing in teaching and learning just the same way that technology has become fascinating and amazing in normal life. Educational technology - the network of computers, world wide web, and others information and communication technology—offer opportunity for learners to access an infinite range of subject matters and experience them in spectacular ways. In addition to technology, artefacts and real-life situations and persons can very well serve as models and powerful instructional resources. Science, mathematics, technology, arts, humanities and other fields of study all have instructional resources that can boost teaching and learning.

\section{Instructional Strategy}

The learning process is founded on teaching methodology. Without appropriate teaching methodology or strategy, the intents and purposes of the curriculum cannot be realized. The commonest situation in the Nigerian school is where the teachers are well trained in their teaching subjects but lack the pedagogy to deliver the knowledge, skills and values required by the subjects. Teaching methodology helps a teacher to transfer or facilitate learning. The methodology operates in form of instructions and that is why it is often referred to as instructional strategy. To make the best of instructional strategy, it is critical to understand what constitutes instruction in the learning system and the styles that instruction may take. These are primarily what this section attempts to establish.

Instruction is the facilitation of a learning process through a combination of communication, interpersonal influence and instructional resources to motivate and enhance the perceptive ability of a learner. Instruction therefore is a complex whole that has important characteristics as follows:

i. Communication-This refers to exchange of meanings, ideas, and information coded in words, gestures and artefacts. Communication is at the heart of instruction. Some communication is wrong while others are right for learning purposes. Emphasis must be on the right communication.

ii. Interpersonal influence - In the context of learning, there is interpersonal influence between and among individuals. This could be direct or indirect or virtual.

iii. Instructional resources-These are aids designed to enhance communication and interpersonal influence in the learning process. The resources are enhancers and often indispensable in learning. A teacher must be aware of what the resources are, their uses, merits and demerits.

iv. Motivation-This is a key character of any good instructional strategy. The strategy must be able to inspire and create interest, curiosity and the spirit of enquiry in the learner. An instruction that fails this 'test', does not stand. With motivation, a learner can embark on discovery with minimal supervision and without coercion. Learning does not require coercion.

v. Perceptive ability - Learning comes through experience using all the senses available to a human being. Instruction must target and engage practically all of these senses as much as possible. Learning comes through, not stories or hearing alone, but also seeing, touching, smelling, feeling, and so forth. Basically, there are five human senses but some list more. The five are sight, hearing, taste, smell and touch. Others are balance and acceleration, temperature and pain, among others.

Since instruction is a complex activity, instructional strategy must vary and depend on given contexts. The contexts include (a) subject matter - concrete, abstract, simple, complex, arts, science, and lesson objectives (b) learner characteristics - age, maturity, socio-economic background, gender, and disability issues; (c) student-teacher ratio; (d) time; (e) available instructional resources-e.g., educational technology; (f) teacher competence; and (g) environment. Therefore, instructional strategies need to well thought-out and dynamic. The same theme or topic may require a combination of strategies and at the long run, a teacher may have used many strategies rather than being fixated on one or a few. The emphasis is "what works." This means that instructional strategies must be evidence-based and not follow mere tradition and presumption.

Actual instructional strategies vary tremendously; thus, it is difficult to have a comprehensive catalogue of strategies. The Center for Teaching and Learning, University of North Carolina at Charlotte (2018) analyzed 
what it called 150 teaching methods which it recommended to its faculty. These include lecture, group discussion, recitation, demonstration, debating, puzzles, panels, flipped classroom, and tutorial. Others are story-telling, quiz, modelling, dramatization, simulation, coaching, projects, field trips, interviews, and over a hundred others. The fact is that these instructional styles are not mutually exclusive, as such, they may be cross-cutting in real life.

Grasha (cited by Gill, 2013) improved the search for instructional styles by classifying them into five. Grasha, a famous professor of educational psychology submitted that all instructional styles may be collapsed into five, which have been widely adopted by other scholars. The categories are: (a) Expert: The teacher is an expert and coaches, shares knowledge, demonstrates, advises, guides and obtains feedback to help improve the instruction. (b) Formal authority: The teacher is an expert and but follows the traditional approach of dishing out lecture with less of student participation. (c)Personal model: The teacher is dynamic and adaptive and blends styles to suit the contexts at hand. (d) Facilitator: The teacher encourages participatory activities and group projects, assist leaners with information, obtaining feedback and ploughing it back to promote critical thinking among the learners. (e) Delegator: The teacher leaves most of the learning activities to self-regulation and control of the learners while providing minimum supervision.

In addition to Grasha's views, other scholars and authorities (Leicester Learning Institute, University of Leicester, 2018; Peterson-DeLuca, 2016; Tersoo, 2018; UNESCO, 2016) equally proposed other categorizations and emphases. For instance, Tersoo (2018) outlined four categories such as teacher-centred, student-centred, high technology and low technology based instructional styles. Leicester Learning Institute, University of Leicester (2018) suggested what it called five top qualities of a great teacher which are (a) Ability to nurture and sustain good relationship with learners; (b) Patience, care and kindness; (c) Good knowledge of learner background; (d) Dedication to teaching; and (f) Constructive engagement of learners. Peterson-DeLuca (2016) listed four categories of instructional styles which are lecture, demonstration, delegator and hybrid. This trend shows that instructional styles may be complex but basically, they also can be conveniently delineated as into a few classes. Basically, a style runs along a continuum which at one end is teacher-centred and at the other end is learner-centred. While a blend of these are always advised the most favoured instructional style in the context of the modern learning system is the learner-centred styles. The latter is believed to bring out the best in the learner and inculcate in them the spirit of enquiry, reflection and critical thinking. Individualised style is another concept that encourages teachers to reach out to learners based on their individual characteristics rather than treat them as a class or group in all respects. The reason is simple - every learner is unique based not only on genetic inheritance but also socio-psychological characteristics which in turn define each learner's needs in the learning process. Some are fast learners while others are slow learners; some have interest in science and others in arts; some perform greatly in speech others are better in writing, and so forth. Therefore, individualized instruction is a powerful concept that advocates that the teachers should pay attention to the uniqueness of the students in the learning process. Lastly, the UNESCO Africa Regional Office, Dakar (2016) competency standards for West and Central Africa are also relevant here. The standards expect that the instructional process in a learning system must adequately cater for following four areas: (a) Lesson preparation; (b) Lesson delivery; (c) Assessment of learning; and (d) Management of extracurricular activities.

\section{Teacher Competency}

In the modern learning system, the teacher is a facilitator and puts the learners at the centre of activities as has been stated earlier. Being a facilitator may sound lightly but it presupposes professionalism. The teacher for the 21 st century is not someone that will stand in front of the class, talking down on the learners, exhuming an all-knowing attitude, using only the lecture style while being largely ignorant of the science and art of teaching. This is why teacher professionalism is the next building block that is indispensable for a model learning system. As in every other discipline, teaching has its own 'secrets' which may be termed the science and arts of teaching as well as its own esoteric language as it is common to all other noble professions. Individuals who are not sufficiently educated in the science and art and who are uninitiated in the profession do not have the academic, intellectual, attitudinal, moral and legal authority to be teachers in the real sense. Incidentally, so much harm has been done to the teaching profession over the years especially in the developing parts of the world including Nigeria where teaching has been seen as an all-comers job. Individuals of diverse manners and temperaments have been drafted to serve as teachers particularly using the explosion in school enrolment or lack of qualified teachers as excuses. But it is a well-known fact that in the advanced countries where teaching and learning had attained enviable heights, no individual can be allowed to take up teaching without passing through the prescribed minimum professional education and in addition obtaining registration and licensing from the appropriate statutory agency. In the developing parts of the world, the other noble professions like Medicine, 
Engineering and Law had fared well because they enjoyed a system of professional education, regulation, registration and licensure which were enforced and the quacks were kept away from the job. The time has come to reposition teaching as a profession to the heights already attained by these other noble professions. Declarations by the critical stakeholders in education at the African continental as well as global levels have established the minimums for the professionalization of teaching in Africa (African Union, 2016; International Task Force on Teachers, 2017; UNESCO Regional Office, Dakar, 2016). These include the urgency to enact laws by the various countries to make teaching a profession legally; establishment of an agency to regulate teaching; and development and implementation of national and continental teacher qualification frameworks and professional standards, among others. Therefore, a teacher in the context of a model learning system must be someone that meets the minimum criteria prescribed by the relevant authorities and stakeholders.

It is further endorsed by all the international authorities cited above that professional teaching standards shall be the pivot of the profession. This implies that professional teaching standards, developed and endorsed at the local, national and international levels shall be the most important point of reference in assessing the credentials of a teacher, evaluating the professional performance, planning for the professional development and designing the professional reward programmes. Professional standards are found in all professions and no profession can attain its vision and mission without having standards. The same now applies to teaching. The professional standards are important framework of the knowledge, skills, attitudes, values and relationships expected of a professional in the context of his or her work (Board of Studies, Teaching and Educational Standards, New South Wales, 2013; Evetts, 2014; Ingersoll \& Perda, 2008; Ontario College of Teachers, 2016). As Bullock and Trombley (1999) cited in Smith $(2009$, p. 2) put it, "a profession arises when any trade or occupation transforms itself through 'the development of formal qualifications based upon education and examinations, the emergence of regulatory bodies with powers to admit and discipline members, and some degree of monopoly rights"'. Therefore, a teacher in the 21 st century must have been educated, tested, proven and licensed based on the professional teaching standards.

The teacher is the most important factor in the teaching-learning process. The competence of the teacher sets the limit to what the learners can do and how much of their potentials can be catalyzed to boom and blossom. It takes a competent and professional teacher to understand and effectively manage the principles and practices (the building blocks) of a model learning system. The importance of learner characteristics, the nature and requirements of a balanced curriculum, instructional strategies, utilization of instructional resources, assessment of learners and all other ramifications of the learning system are well under the grasp of a competent professional teacher. This is not true for the 'teacher' who has no tested and proven competencies.

\section{School Climate}

Learning does not take place in a vacuum: It occurs within the school social milieu. This milieu is a factor that significantly determines whether or not learning takes place. The school has cultures and culture is basically defined as a way of life of a people which includes their physical creations such as architecture, dresses, music, and other artefacts as well as the abstract creations such as language, beliefs, norms and values. The more the culture of a school or classroom matches the culture of the learner the greater the chances that great learning will take place. Conversely, a school with alien culture, or worse still with culture that is antagonistic and denigrate the culture of the learner creates tension, apprehension, low self-esteem and eventually poor learning outcome. In most cases, the learner may also drop out of school or not attend at all. For this reason, the social climate of the school is part of the building blocks of a model learning system.

One of the most powerful components of culture is language. Learning must be founded upon the mother tongue of the learner and then gradually advance to national and international standards required for professional callings and advanced learning. Other important components of culture that are essential for great leaning are trust, empathy and interdependence. The school environment is not just physical but also has socio-psychological dimensions. Indeed, the physical environment is critical to build upon, but perhaps the socio-psychological atmosphere of the school is extremely important too. The school climate can be likened to the climate in the physical world: both have their rainy and sunny days. This means that no school climate can be perfect - there are bound to be tides of happy and sad moments as obtains in the normal life. However, the benchmark is that in all situations, the school should maintain the love, trust, empathy and mutual dependence equivalent to that of a family. This is why the teachers' roles is said to be "loco-parentis" which is a Latin word meaning "in the place of a parent". Teachers are expected to take the place of the parents of their students and to treat the students exactly as they would treat their own children. The school is expected to implement their vision of multiculturalism in practice and to give every learner opportunity to feel loved, wanted and encouraged to excel. This is a necessary condition for high impact learning and academic performance. 
Furthermore, these days there is so much to worry about the physical safety of students in the school environment. The threats from the terrorists, kidnappers, pedophiles and ritualists are palpable and at times, "teachers" and "principals" have been found to be among such offenders. Yet there is also the psycho-social trauma inflicted on the child in schools in form of corporal punishments. Some cases of abuse of the child at school had gone viral on the internet and drawn condemnations from the public. The abuses breed a hostile school environment which impact negatively on learning outcome.

\section{Learning Assessment and Reward System}

Performance and reward are intricately linked. In that linkage, a model learning system must demonstrate unequivocally that there is equity, fair play and justice both in assessment and reward. It must further demonstrate that reward is directly proportionate to performance or simply put, that reward is based on merit. Thus, reward drives the motivation phenomenon which in turn determines that quantum of effort to excel. Learners will exert more effort if they believe that there is justice in the assessment and reward system. Most importantly, a model learning system must also promote signification rewards for high performance. The higher the reward that comes from excellent performance the more the learners will strive to attain greater achievements. In a nutshell, the principle could be expressed mathematically thus: Motivation = Equity (Assessment) $\mathrm{x}$ Value of Reward, or

$$
\mathrm{M}=\mathrm{E}(\mathrm{A}) \mathrm{x} \mathrm{V}
$$

This implies that in a learning system, motivation is a function of equity in assessment multiplied by the value of the reward. Equity in assessment entails being fair and just to all learners and ensuring that learner individual characteristics and multicultural factors are considered in designing and administering tests and other assessments. Where the content of assessment and strategies of administration are not in tandem with the characteristics of learners, they are $a b$ initio invalid and unreliable and cannot be said to be equitable. Therefore, equity stands for fairness in assessment (in relation to each learners' background) and ensuring that there is no favouritism and bias in the assessment system. Like case of instructional strategies, there are a myriad of assessment strategies and these must be carefully weighed and determined based on the context of the assessment such as class size, learner characteristics, assessment resources, language of instruction and other factors (Education International, 2015). Finally, the purpose of learning assessment is not punitive measures or witch-hunting. Rather, it is to promote learning and to guide, counsel and determine plausible remedies for weak learners. Thus, the UNESCO Regional Office, Dakar (2018) advocated a shift from "assessment of learning" to "assessment for learning". The later is a positive view of assessment where it is used primarily to inspire and motivate hard work and to give support to learners with special needs.

\section{Conclusion}

The discourse has given an overview of critical pillars that can empower a model learning system. It has taken, most importantly, issues such as learner characteristics, curriculum development, instructional resources, instructional strategies, teacher competency, assessment strategies and reward system. These are believed to be the secrets of high performing learning systems and the narratives in the paper can serve as a significant guide towards improving the performance of the schools in Nigeria. As stated earlier, the building blocks are like universal principles that work across time and place. They are also based on the relevant theories and assumptions about human nature and the theories and principles of learning. However, the paper does not claim to have discussed exhaustively every issue in the learning system that matters. The learning system is a complex phenomenon affected by many issues from human nature to technology, culture, environment, economics and politics among others. Therefore, no single paper or narrative can claim to have dealt thoroughly with all the significant factors that affect the system. Nevertheless, the issues covered in this paper are the broad pillars upon the learning system stands. If much of the analysis and advocacies in the paper are conscientiously implemented there is a guarantee that learning will improve quite significantly. It is also fascinating that the learning systems in all settings (rural or urban, rich or poor, advanced or developing settings) can apply the issues analyzed to improve their performance.

\section{References}

Ademola, A. A. (2017). Education: Between exclusive and concurrent list. The Nation Newspapers, February 5. Retrieved from http://thenationonlineng.net/education-exclusive-concurrent-list/

African Union. (2016). Recommendations on the AU study of teachers' training, working and living conditions in member states. Addis Ababa: AU. 
Bashir, S., Lockheed, M., Ninan, E., \& Tan, J. (2018). Facing forward: Schooling for learning in Africa. Washington, DC.: World Bank. https://doi.org/10.1596/978-1-4648-1260-6

Bates, C. M. F. (2015). Learner characteristics and motivation: How to achieve efficient and effective learning. Collected Essays on Learning and Teaching, III, 165-170. https://doi.org/10.22329/celt.v8i0.4233

Board of Studies, Teaching and Educational Standards, New South Wales (2013). Australian professional standards for teachers. Sydney: BOSTES

Bullock, A., \& Trombley, S. (1999). The new Fontana dictionary of modern thought. London: Harper-Collins.

Center for Teaching and Learning, The University of North Carolina at Charlotte. (2018). 150 Teaching methods. Retrieved from https://teaching.uncc.edu/.../teaching.../InstructionalMethods/150TeachingMethods.pd

Confucius. (551 BC-479 BC). I hear and I forget. I see and I remember. I do and I understand. Retrieved from https://www.brainyquote.com/quotes/confucius_136802

Education International. (2015). Education for all and the global development agenda beyond 2015. Brussels: EI.

Educorp World. (2018). Convergence summit: Driving a new public education initiative for Nigeria, held in Abuja, November 14-16. Retrieved from http://www.convergencesummit.org

Evetts, J. (2014). The Concept of professionalism: Professional work, professional practice and learning. In S. Billett, C. Harteis \& H. Gruber (Eds.), International handbook of research in professional and practice-based learning (pp. 29-56). Springer international handbooks of education. https://doi.org/10.1007/978-94-017-8902-8_2

Federal Republic of Nigeria. (1999). Constitution of the Federal Republic of Nigeria. Abuja: Government Printer.

Federal Republic of Nigeria. (2013). National policy on education. Abuja: NERDC.

Gill, E. (2013). What is your teaching style? 5 Effective teaching methods for your classroom. Retrieved from https:/education.cu-portland.edu/blog/classroom-resources/5-types-of-classroom-teaching-styles/

Independent Newspapers. (2017). Let education remain on concurrent list: Editorial opinion. January 31. Retrieved from https:/www.independent.ng/let-education-remain-on-concurrent-list/

Ingersoll, R. M., \& Perda, D. (2008). The status of teaching as a profession. In B. Jeanne \& S. Joan (Eds.), Schools and society: A sociological approach to education (pp. 106-118). Los Angeles: Pine Forge Press.

International Task Force on Teachers. (2017). Declaration of the 10th Annual Policy Dialogue Forum held in Lome, Togo, September 18-22.

Jackson, P. W. (1968). Life in classrooms. New York: Holt Rinehart and Winston.

Leicester Learning Institute, University of Leicester. (2018). Effective teaching strategies. Retrieved from https:/www2.le.ac.uk/offices/lli/developing-learning-and-teaching/enhance/strategies

Nwokeocha, S. (2018) Integration of African indigenous cultures in curriculum content and implementation in sub-Saharan Africa. In N. K. Theresa \& M. N. Uchenna (Eds.), Issues in curriculum development and implementation in Nigeria: A book of readings in honour of Prof U.M.O Ivowi (pp. 290-302). Lagos: Foremost Educational Services Limited.

Nwokeocha, S. (2019). Multicultural education for sustainable development. In U. M.O Ivowi (Ed.), Educating for functionality: Readings in honour of Prof. P.A.I Obanya. Abuja: Nigerian Academy of Education.

Obanya, P. A. I (2005). Culture in education and education in culture. Paper presented at the 5th Conference of the African Ministers of Culture, Nairobi, Kenya, 10-14 December.

Ontario College of Teachers. (2016). The standards of practice for the teaching profession. Retrieved from https://www.oct.ca/

Peterson-DeLuca, A. (2016). Top five qualities of effective teachers, according to students. Retrieved from https://www.pearsoned.com/top-five-qualities-effective-teachers/

Ray, B. D. (2018). Research facts on homeschooling. National Home Education Research Institute. Retrieved from https://www.nheri.org/research-facts-on-homeschooling/

Rurato, P., \& Gouveia, L. B. (2014). The importance of the learner's characteristics in distance learning environments: A case study. Researchgate, June. https://doi.org/10.1109/CISTI.2014.6876960 
Sarwar, S. (2013). What motivates 21st century Muslim parents to home-educate their children? Education Today, 63(4), 25-29.

Schrum, L., \& Hong, S. (2002). From the field: Characteristics of successful tertiary online students and strategies of experienced online educators. Education and Information Technologies, 7(1), 5-16. Retrieved from http://www.springerlink.com/content/?k=Schrum

Smith, E. (2009). Increasing our depth, breadth, and value-DMBOK and CDMP for Data Professionals. Paper presented at the San Francisco DAMA Day, December 16. Retrieved from http://www.sfdama.org/Presentations/2009/DAMA\%20Day/SF\%202009\%20DAMA\%20Day\%20Slides\%2 0ICCP\%201206.pdf

Tersoo, A. (2018). Types of teaching methods, their advantages and disadvantages. Retrieved from https://www.legit.ng/1143440-types-teaching-methods-advantages-disadvantages.html

UNESCO. (2013). Education transforms lives. Paris: Author.

UNESCO. (2015). Rethinking education: Towards a common global good? Paris: Author.

UNESCO. (2017). Unpacking sustainable development goal 4-Education 2030. Paris: UNESCO.

UNESCO Institute for Statistics. (2018). Handbook on measuring equity in education. Montreal: Author.

UNESCO Regional Office, Dakar. (2016). Summary report on the establishment of certification standards for basic education teachers in ECOWAS countries. Dakar: Author.

UNESCO Regional Office, Dakar, Senegal. (2018). Teaching and Learning Educators' Network for Transformation (TALENT). Dakar: UNESCO.

United Nations. (1948). Universal declaration of human rights. New York: UN.

United Nations. (2015). Transforming our world: The 2030 agenda for sustainable development. New York: UN.

United Nations Girls Education Initiative. (2010). Equity and inclusion in education: A guide to support education sector plan preparation, revision, and appraisal. Washington, D.C.: Author.

United States National Center for Education Statistics. (2017). Retrieved from https://nces.ed.gov/

Weibelzahl, S., \& Kelly, D. (2005). Adaptation to motivational states in educational systems. In Proceedings of the Workshop week Lernen-Wissensentdeckung-Adaptivat (LWA2005, pp. 80-84). Saarland University, Saarbrucken.

\section{Copyrights}

Copyright for this article is retained by the author, with first publication rights granted to the journal.

This is an open-access article distributed under the terms and conditions of the Creative Commons Attribution license (http://creativecommons.org/licenses/by/4.0/). 